\title{
A questionnaire on pelvic floor dysfunction postpartum
}

\author{
Charlotte Luthander • Thomas Emilsson • \\ Gunnar Ljunggren • Margareta Hammarström
}

Received: 25 November 2009/Accepted: 30 July 2010 /Published online: 27 August 2010

(C) The Author(s) 2010. This article is published with open access at Springerlink.com

\begin{abstract}
Introduction and hypothesis The incidence of obstetric anal sphincter injuries is used in Sweden as a measurement of quality of care and this might influence the reporting. However, the correlation between reported diagnosis of pelvic floor injury at delivery and pelvic floor symptoms a year later is unknown. A questionnaire could identify such symptoms and provide beneficial feedback to obstetrical practices.

Methods We made a cross-sectional study by sending out a questionnaire about pelvic floor dysfunction to 599 women depending on reported injury at delivery. The answers provided by the groups were then compared.

Results The questionnaire identified women with pelvic floor dysfunction. Anal incontinence was most common among women with obstetric anal sphincter injuries but also occurred among women delivered vaginally without known tears.
\end{abstract}

\footnotetext{
C. Luthander $(\bowtie)$

Södersjukhuset, Division of Obstetrics and Gynaecology,

Sjukhusbacken 10S-11883,

Stockholm, Sweden

e-mail: charlotte.luthander@sodersjukhuset.se

T. Emilsson

Stockholm County Council,

Stockholm, Sweden

G. Ljunggren

Karolinska Institute, Medical Management Centre,

Stockholm, Sweden

M. Hammarström

Karolinska Institute, Department of Clinical Science

and Education, Södersjukhuset, Section of Obstetrics

and Gynaecology,

Stockholm, Sweden
}

Conclusion We suggest that a questionnaire is used 12 18 months after delivery to establish the short-time outcome in terms of pelvic floor dysfunction.

Keywords Cross-sectional study - Obstetric anal sphincter injuries · Primiparas · Pelvic floor symptoms · Questionnaire

$\begin{array}{ll}\text { Abbreviations } \\ \text { OASIS } & \text { Obstetric anal sphincter injuries } \\ \text { PF } & \text { Pelvic floor } \\ \text { PFD } & \text { Pelvic floor dysfunction } \\ \text { SUI } & \text { Stress urinary incontinence } \\ \text { UUI } & \text { Urge urinary incontinence } \\ \text { BMI } & \text { Body mass index }\end{array}$

\section{Introduction}

Female pelvic floor dysfunction with symptoms such as urinary and anal incontinence as well as prolapse symptoms causes major discomfort and embarrassment [1-4]. Vaginal delivery in itself and large tears in the pelvic floor and perineum in particular are important contributing factors. Obstetric anal sphincter injuries (OASIS) have received increasing attention during the last two decades [5-7]. The reported incidence of clinically detected OASIS varies from $0.36 \%$ of vaginal deliveries in Finland $[8]$ to $6 \%[9,10]$ in other western countries. Delivering your first baby is the greatest risk factor for OASIS $[9,11,12]$ and among primiparous women the incidence has been reported to be as high as $24 \%[13,14]$. With the addition of endoanal ultrasonography as a diagnostic tool when examining women, the incidence of diagnosed OASIS increases to about $40 \%[6,14,15]$. 
In Sweden the incidence of OASIS has been reported annually to the National Board of Swedish Health and Welfare and also to the Stockholm County Council since 1990 as a measurement of quality of obstetric care. The value of this reported figure is open to debate, since the incidence increases during study periods indicating that greater knowledge about the condition may enhance the ability to identify and willingness to report every OASIS [9, $13,14,16]$. A low figure may consequently reflect good obstetric care but can also possibly be an indication of overlooked cases of OASIS, and the figure might thus be ambiguous in terms of a measurement of quality. Considering the fact that diagnosing otherwise overlooked OASIS reduces the risk of anal incontinence after childbirth [15], we could presume that second best, after prevention of OASIS, is at least detection followed by suturing. We therefore made the assumption that purely striving for a low incidence of OASIS is questionable, and that a tool to measure quality of obstetric care in terms of pelvic floor dysfunction symptoms would be of value. We offered, and were commissioned by, the Stockholm County Council to construct a questionnaire and to evaluate if it could be used as a tool for detecting symptoms of OASIS and its complications, giving a more accurate assessment of quality of delivery care than the incidence alone.

\section{Material and methods}

OASIS is divided into 4 degrees (16 WHO1992). The first degree involves only the vaginal mucous membrane and the perineal skin, and the second-degree tear involves the fascia and muscle of the perineal body but not the anal sphincters. The third degree tear involves the anal sphincters and is further divided into (1) a partial tear of the anal sphincters and (2) a complete tear of the external and internal anal sphincters. The fourth-degree tear involves the anal or rectal mucosa.

The outline of the study design is shown in Fig. 1. The study was based on all primiparas delivered from April 1 2006 to March 312007 in the Stockholm County in which all six delivery units share the same computerized medical record system and which is connected to a statistical program, Business Object (BO). Through $\mathrm{BO}$ we could trace the desired target groups. The questionnaire was sent out during two periods: in October 2007, reaching women delivered from April 1st 2006 until September 30th 2006, and in April 2008 reaching women who gave birth from October 1st 2006 until March 30th 2007. We wanted the questionnaire to reach the women 12-18 months after their first delivery since we assumed that, at this time, most women have stopped breastfeeding, they menstruate again, lacerations are healed and further improvement of symp- toms from the pelvic floor cannot be expected. In addition, most women have not yet delivered a second time.

The incidence of OASIS in vaginally delivered primiparas in Stockholm during 2006 was reported to be $7.6 \%$ in the National Medical Birth Register. From this the estimated number of women sustaining a complete OASIS during the study period was calculated to be approximately 140. All women who were diagnosed as having sustained a complete obstetric anal sphincter injury (degree IIIB and degree IV) were invited and comprised group 1, $(n=106)$.

Women randomly selected among those who sustained a partial OASIS (degree IIIA) constituted group $2(n=137)$. As control groups we used randomly selected women delivered by either elective cesarean section due to breech presentation (group $3(n=176)$ ) or by a normal vaginal delivery without a diagnosed tear larger than grade 2 (group $4(n=184)$.Women delivered before gestational week 37 or with an intrauterine fetal death were excluded. The oversampling of women delivered vaginally with no reported OASIS and by elective cesarean section was done to increase the efficiency of the study since we suspected they might report fewer symptoms. All women were sent the questionnaire by mail and the women who failed to respond were sent two reminders.

The questionnaire consisted of three parts, the first including four questions which had previously been used to identify women with urinary leakage or prolapse [17, 18]. The questions about urinary leakage were: "Do you occasionally experience urinary leakage?" (U1); and "Did you experience urinary leakage before pregnancy?" (U2). "Do you occasionally experience an emergent need to urinate and then have difficulties reaching the toilet in time?" (U3) An additional question was; "Do you leak urine when coughing, sneezing, lifting or during physical activities?" (U4)

For urinary incontinence we used the answer alternatives "never", "some time every month", "some time every week", and "daily". Incontinence once a week or more often was used as the definition of incontinence, in line with the suggestion by Fornell et al. [19] that this definition could be used in populations where objective signs are not available on record. An affirmative answer to question U4 served to define stress urinary incontinence (SUI) and an affirmative answer to question U3 served to define urge urinary incontinence (UUI).

For prolapse symptoms we used the question "Do you have a sensation of tissue protrusion (vaginal bulge) from the vagina" (U5) with the answer alternatives "no", "some time every month", "some time every week", "daily". The answer "some time every week" or "daily" served to define symptoms and"no" or"once a month" defined no symptoms.

The second part of the questionnaire dealt with anal incontinence using the modified Wexner score [20] which 
Fig. 1 Outline of study design and participants accrual

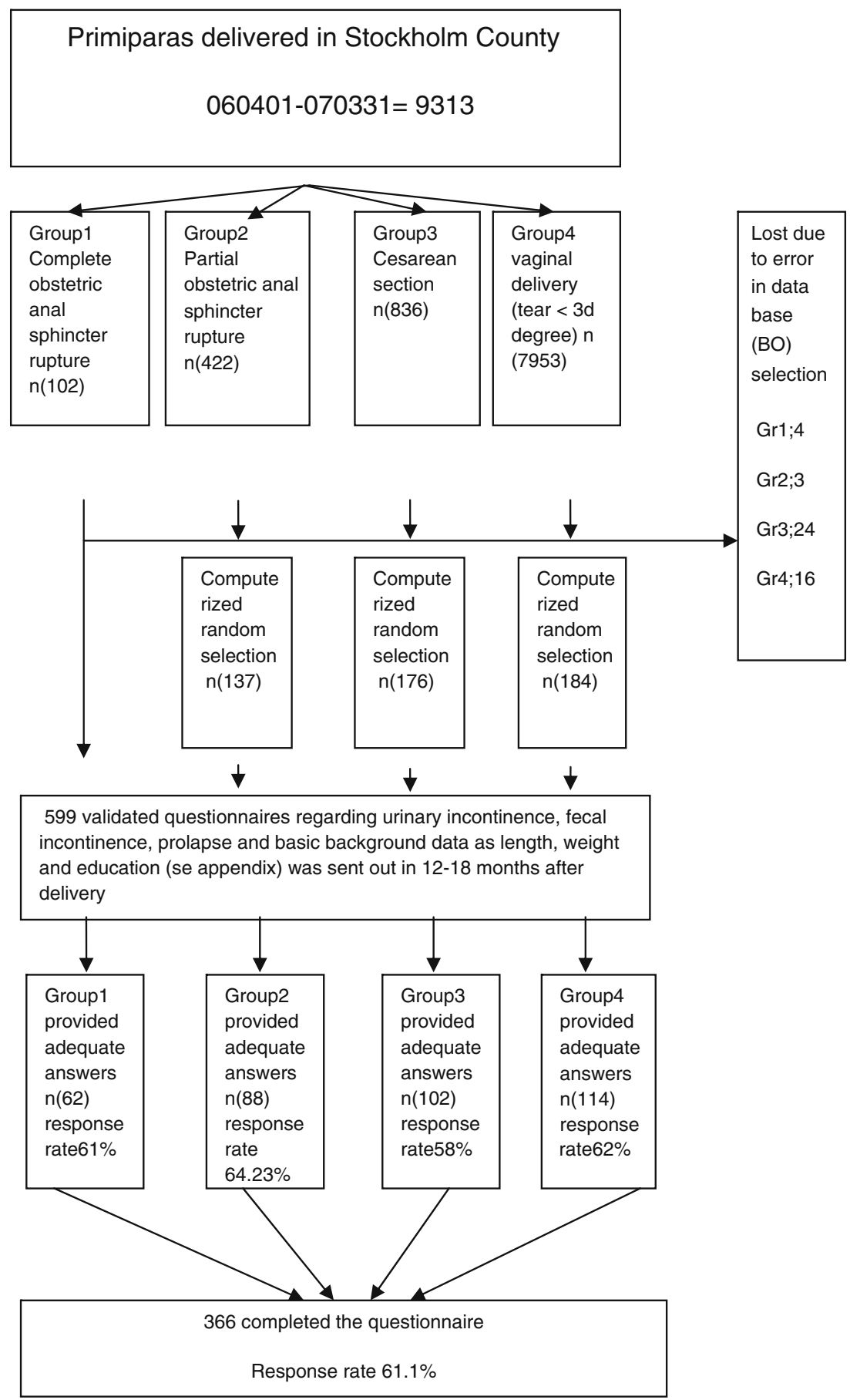

includes questions about involuntary leakage of gas, liquid and solid stools, the need to wear pads and if lifestyle alterations are being made due to incontinence. These questions have not been validated in Swedish but are frequently used in similar studies in other languages [10, 15, 21].

For anal incontinence we used four questions: "Do you occasionally experience solid stools leakage?" (A1) "Do you occasionally experience liquid stools leakage?"(A2)
"Do you occasionally involuntarily leak gas" (A3) and "Do you use pads due to bowel leakage?" (A4) For lifestyle alterations we asked "Is there anything that you must avoid due to anxiety about gas -and/or anal leakage, for example walks, physical activity, swimming, courses or professional work?" (A5) The answer alternatives were: "no", "some time every month", "some time every week", and "daily". For anal incontinence the answers "some time every 
month" or "some time every week" or "daily" served to define symptoms, since we postulated that fertile women very seldom report anal incontinence and also that infrequent fecal leakage is bothersome [5].

The third part concerned background data about height, weight, self-evaluated health, native language and level of education. The BMI variable was divided in four categories; $<19,19-25,>25-30$, and $>30$.

To test the comprehensibility of the questionnaire we randomly selected two to three women in each of the four study groups, ten women in all. During a personal meeting they filled in the questionnaire together with one of the members of the study group specialized in validating forms. In this pilot study the questions proved to be understandable and the alternatives easily distinguishable.

Statistics: The difference in proportion of symptomatic women between the two populations in groups 1 and 2 was set at 0.20 , as this was the smallest effect that would be clinically important to detect. Assuming the above-mentioned difference in proportions, 93 patients were needed in each group, given that the significance level was set at $5 \%$, and the power at $80 \%$." The statistical method used was Chi-square test or Fisher's exact test when the expected value in the cells was more than 1 (which was the case primarily in the questions about incontinence). One-way analysis of variance was used to evaluate any contingent difference in (mean) BMI between the four groups. Statistical computing was done using SPSS version 17.

The study was approved by The Ethics Committee at Karolinska Institutet (2007/1228-31/4 October 31st 2007)

\section{Results}

The questionnaire was completed by the same percentage of women in all the groups, in total 366 women, giving a response rate of $61.1 \%$ (Fig. 1). Mean age and diagnosis among responders and non-responders is presented in Table 1 which shows that there were no significant differences between the groups in this respect.

Table 1 Mean age (range) and diagnosis for responders and nonresponders

\begin{tabular}{llr}
\hline & $\begin{array}{l}\text { Age of } \\
\text { responders } \\
(N(366))\end{array}$ & $\begin{array}{l}\text { Age of non- } \\
\text { responders } \\
(N(229))\end{array}$ \\
\hline Group 1, complete OASIS & $32.2(24-41)$ & $30(18-40)$ \\
Group 2, partial OASIS & $30.2(20-40)$ & $29(20-41)$ \\
$\begin{array}{l}\text { Group 3, elective c-section } \\
\text { Group 4, vaginal delivery tear } \\
<\text { 2nd degree }\end{array}$ & $30.5(19-46)$ & $32.2(19-44)$ \\
\hline
\end{tabular}

Obstetric anal sphincter ruptures (OASIS)
The background data are presented in Table 2. Out of the 366 women $16.3 \%$ (54) were pregnant again when answering the questionnaire; $63.7 \%$ (232) of the women were university graduates.BMI was categorized into four intervals but no significant differences between the groups were seen in any of the background parameters.

Urinary incontinence

Very few women reported urinary leakage before pregnancy and there were no differences between the groups (Table 3).

Occasional leakage of urine was reported to be equally common in each group 1 year postpartum. Urge urinary incontinence (UUI) was not significantly different between the groups either and was reported by $8.2 \%$ (5) in group 1 and $10.2 \%$ (9) in group 2, by $5.9 \%$ (6) in group 3 and by $12.3 \%$ (14) in group 4 (n.s.).

The significantly lowest incidence of stress urinary incontinence (SUI) was found among women in group 3 and was reported weekly/daily by $19.4 \%$ (12) in group 1 , $12.5 \%$ (11)in group 2, $4.0 \%$ (4) in group 3 and $14.0 \%$ (16) in group $4(P=0.019)$ (Table 3$)$.

\section{Prolapse symptoms}

The sense of vaginal bulge was significantly higher in group 1 which comprised those who had a complete OASIS compared to group 2. No one in group 3 reported this complaint. Notably five women in group 4 reported prolapse symptoms 1 year postpartum (Table 3 ).

Anal incontinence

In this survey none of the women who sustained a complete OASIS suffered from frank solid stool leakage 12 18 months after their first delivery while $4.5 \%$ (4) in group $2,1.0 \%$ (1) in group 3, and notably $2.6 \%$ (3) in group 4 reported solid stool leakage $(p=0,218)$ (Table 4$)$.

The symptom of liquid stools leakage was more frequent and was reported mainly among women with a reported obstetric tear; by $17.7 \%$ (11) women in group 1, 17.0\% (15) in group 2 and six women each in groups 3 and $4 ; 5.9 \%$ and $5.3 \%$, respectively $(P=0.004)$. The symptom of flatus incontinence occurred in $75.8 \%$ (47) of women in group 1, $53.4 \%$ (47) in group 2, 27.5\% (28) in group 3 and 31\% (35) in group $4(P=0,000)$ (Table 4$)$.

The need to wear pads was significantly more often reported by women with a severe OASIS, group $1(6.5 \%$ (4), $P=0,011$ ) (Table 4). When testing frequency of symptoms in terms of no/every month/every week/daily and comparing the groups the results did not change, however the groups were very small, see Table 5 . 
Table 2 Cross-tabulation demographic percentage of data $(n)$

\begin{tabular}{|c|c|c|c|c|c|}
\hline & $\begin{array}{l}\text { Complete OASIS } \\
\text { group }(1 \%(n))\end{array}$ & $\begin{array}{l}\text { Partial OASIS } \\
\text { group }(2 \%(n))\end{array}$ & $\begin{array}{l}\text { Elective C-s } \\
\text { group }(3 \%(n))\end{array}$ & $\begin{array}{l}\text { Vaginal delivery } \\
\text { tear }<2 \text { degree group }(4 \%(n))\end{array}$ & $P$ value \\
\hline \multicolumn{5}{|l|}{ Are you pregnant now? } & \multirow[t]{3}{*}{0.668} \\
\hline Yes & $19.7(12)$ & $18.2(16)$ & $13.7(14)$ & $14.3(16)$ & \\
\hline No & $80.3(49)$ & $81.8(72)$ & $86.3(88)$ & $85.7(96)$ & \\
\hline \multicolumn{5}{|l|}{ BMI } & \multirow[t]{5}{*}{0.053} \\
\hline$<19$ & $6.5(4)$ & $8.0(7)$ & $11.9(12)$ & $6.3(7)$ & \\
\hline $19-25$ & $72.6(45)$ & $65.5(57)$ & $63.4(64)$ & $70.3(78)$ & \\
\hline$>25-30$ & $17.7(11)$ & $21.8(19)$ & $12.9(13)$ & $21.6(24)$ & \\
\hline$>30$ & $3.2(2)$ & $4.6(4)$ & $11.9(12)$ & $1.8(2)$ & \\
\hline \multicolumn{5}{|l|}{ Self-assessed health } & \multirow[t]{6}{*}{0.722} \\
\hline Excellent & $11.3(7)$ & $19.3(17)$ & $18.0(18)$ & $24.1(27)$ & \\
\hline Very good & $54.8(34)$ & $46.6(41)$ & $48.0(48)$ & $49.1(55)$ & \\
\hline Good & $27.4(17)$ & $28.4(25)$ & $26.0(26)$ & $22.3(25)$ & \\
\hline Fair & $6.5(4)$ & $3.4(3)$ & $7.0(7)$ & $3.6(4)$ & \\
\hline Poor & $0.0(0)$ & $2.3(2)$ & $1.0(1)$ & $0.9(1)$ & \\
\hline \multicolumn{5}{|c|}{ Is Swedish your native language? } & \multirow[t]{3}{*}{0.0537} \\
\hline Yes & $87.1(54)$ & $78.4(69)$ & $84.3(86)$ & $82.3(93)$ & \\
\hline No & $12.9(8)$ & $21.6(19)$ & $15.7(16)$ & $17.7(20)$ & \\
\hline \multicolumn{5}{|c|}{ Highest completed education } & \multirow[t]{4}{*}{0.163} \\
\hline Elementary school & $3.2(2)$ & $6.8(6)$ & $4.0(4)$ & $1.8(2)$ & \\
\hline High school & $21.0(13)$ & $31.8(28)$ & $32.7(33)$ & $38.9(44)$ & \\
\hline University & $75.8(47)$ & $6.4(54)$ & $63.4(64)$ & $59.3(67)$ & \\
\hline
\end{tabular}

There were no differences between the groups concerning background data. Body mass index (BMI), obstetric anal sphincter ruptures (OASIS)

Table 3 Urinary incontinence reported in the four different groups

\begin{tabular}{|c|c|c|c|c|c|}
\hline & $\begin{array}{l}\text { Complete OASIS } \\
\text { group }(1 \%(n))\end{array}$ & $\begin{array}{l}\text { Partial OASIS } \\
\text { group }(2 \%(n))\end{array}$ & $\begin{array}{l}\text { Elective c-s } \\
\text { group }(3 \%(n))\end{array}$ & $\begin{array}{l}\text { Vaginal delivery, tear } \\
<2 \text { degree group }(4 \%(n))\end{array}$ & $P$ value \\
\hline \multicolumn{5}{|l|}{ U1 occasionally leak urine } & \multirow[t]{3}{*}{0.093} \\
\hline No/every month & $81.7(49)$ & $81.8(72)$ & $93.0(93)$ & $86.6(97)$ & \\
\hline every week/daily & $18.3(11)$ & $18.2(16)$ & $7(7)$ & $13.4(15)$ & \\
\hline \multirow{2}{*}{\multicolumn{5}{|c|}{$\begin{array}{l}\text { U2 before pregnancy } \\
\text { no/every month }\end{array}$}} & \multirow[t]{3}{*}{0.124} \\
\hline & $95.2(59)$ & 100 & $97.0(98)$ & $99.1(112)$ & \\
\hline every week/daily & $4.8(3)$ & 0 & $3.0(3)$ & $0.9(1)$ & \\
\hline \multicolumn{5}{|l|}{ U3 Urge incontinence } & \multirow[t]{3}{*}{0.426} \\
\hline No/every month & $91.8(56)$ & $89.8(79)$ & $94.1(96)$ & $87.7(100)$ & \\
\hline Every week/daily & $8.2(5)$ & $10.2(9)$ & $5.9(6)$ & $12.3(14)$ & \\
\hline \multicolumn{5}{|l|}{ U4 Stress incontinence } & \multirow[t]{3}{*}{0.019} \\
\hline No/every month & $80.6(50)$ & $87.5(77)$ & $96.0(97)$ & $86.0(98)$ & \\
\hline Every week/daily & $19.4(12)$ & $12.5(11)$ & $4.0(4)$ & $14.0(16)$ & \\
\hline \multicolumn{5}{|l|}{ U5 vaginal bulge } & \multirow[t]{3}{*}{0.010} \\
\hline No/every month & $90.2(55)$ & $97.7(86)$ & 100.0 & 95.5 (107) & \\
\hline Every week/daily & $9.8(6)$ & $2.3(2)$ & $0(102)$ & $4.5(5)$ & \\
\hline
\end{tabular}

There were no differences between the groups before pregnancy. Stress urinary incontinence and prolapse symptoms were seldom noted among women delivered by a caesarean section, but were among women with any vaginal tear. Note that women with no reported obstetric anal sphincter rupture (OASIS) also complained of prolapse symptoms which might indicate missed OASIS or severe vaginal tears 
Table 4 Anal incontinence in the four different groups

\begin{tabular}{|c|c|c|c|c|c|}
\hline & $\begin{array}{l}\text { Complete OASIS } \\
\text { Group } 1\end{array}$ & $\begin{array}{l}\text { Partial OASIS } \\
\text { Group } 2\end{array}$ & $\begin{array}{l}\text { Elective caesarean section } \\
\text { Group } 3\end{array}$ & $\begin{array}{l}\text { Vaginal delivery tear } \\
<2 \text { degree } \\
\text { Group } 4\end{array}$ & $P$ value \\
\hline \multicolumn{5}{|l|}{ A1 solid stools } & \multirow[t]{3}{*}{0.218} \\
\hline No & $100(61)$ & $95.5(84)$ & $99.0(101)$ & $97.4(111)$ & \\
\hline Every month/every week/daily & 0 & $4.5(4)$ & $1.0(1)$ & $2.6(3)$ & \\
\hline \multicolumn{5}{|l|}{ A2 liquid stools } & \multirow[t]{3}{*}{0.004} \\
\hline No & $82.3(51)$ & $83.0(73)$ & $94.1(96)$ & $94.7(108)$ & \\
\hline Every month/every week/daily & $17.7(11)$ & $17.0(15)$ & $5.9(6)$ & $5.3(6)$ & \\
\hline \multicolumn{5}{|l|}{$\mathrm{A} 3$ gas } & \multirow[t]{3}{*}{$<0.000$} \\
\hline No & $24.2(15)$ & $46.6(41)$ & $72.5(74)$ & $69.0(78)$ & \\
\hline Every month/every week/daily & $75.8(47)$ & $53.4(47)$ & $27.5(28)$ & $31.0(35)$ & \\
\hline \multicolumn{5}{|l|}{ A4 pads } & \multirow[t]{3}{*}{0.011} \\
\hline No & $93.5(58)$ & $98.9(87)$ & $99.0(101)$ & $100.0(113)$ & \\
\hline Every month/every week/daily & $6.5(4)$ & $1.1(1)$ & $1.0(1)$ & 0 & \\
\hline \multicolumn{5}{|l|}{ A5 lifestyle alteration } & \multirow[t]{3}{*}{0.075} \\
\hline No & $88.7(55)$ & $95.5(84)$ & $96.1(98)$ & $97.4(111)$ & \\
\hline Every month/every week/daily & $11.3(7)$ & $4.5(4)$ & $3.9(4)$ & $2.6(3)$ & \\
\hline
\end{tabular}

Leakage of liquid stools was more often observed among women with obstetric anal sphincter ruptures (OASIS). Also leakage of gas was more common in these two groups, while women in the group having had a complete OASIS more often used sanitary pads

Table 5 Descriptive statistics

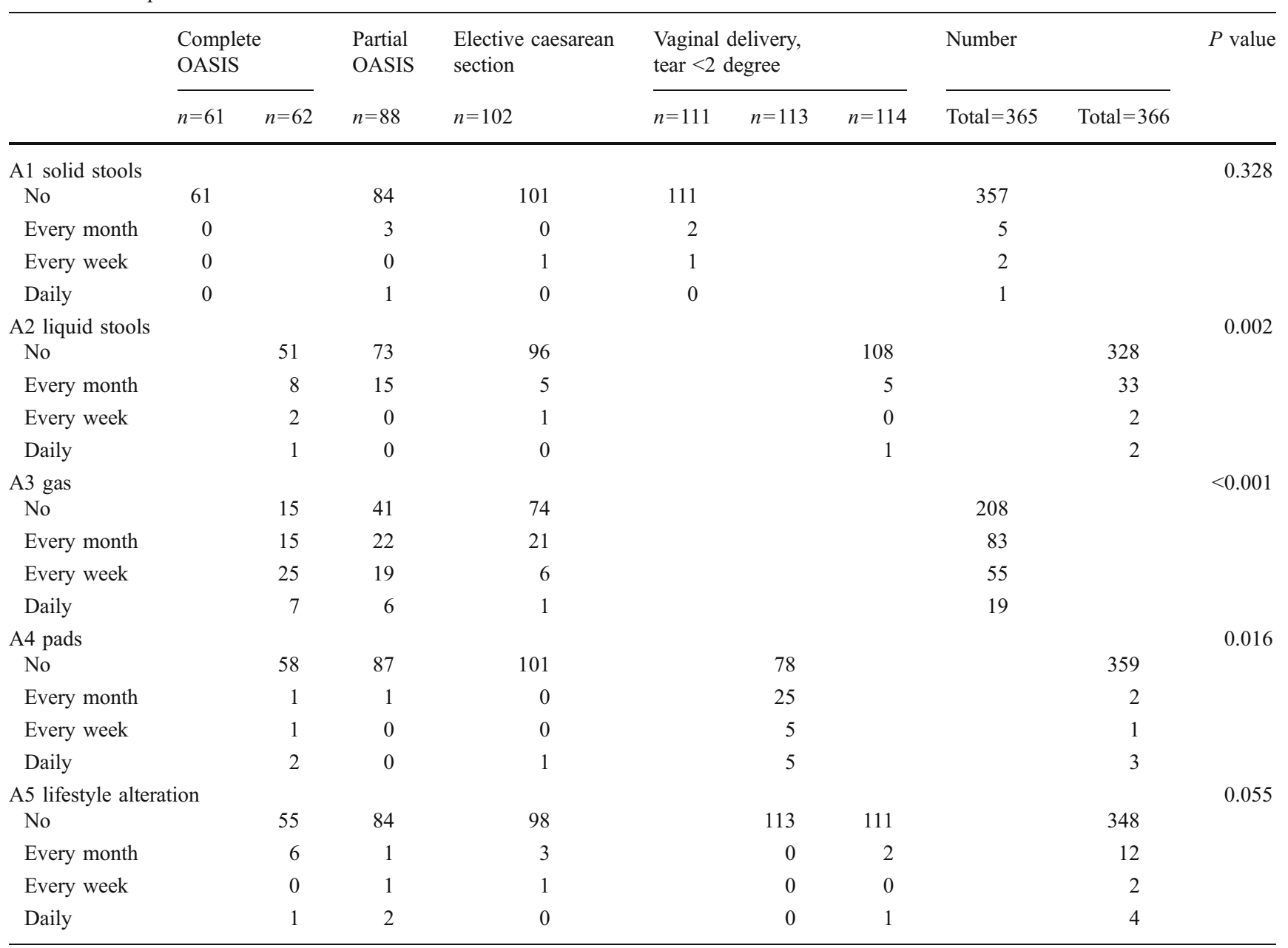

Anal incontinence in the four groups. Since there are few women in each group reporting symptoms, interpretation of data is difficult 


\section{Discussion}

We found it a challenge to evaluate the women's experiences of pelvic floor symptoms in relation to the reported perineal tear after delivery. Sampling four groups of women with reported different severity of the perineal tear, we assumed that the answers would represent the obstetric trauma. Our hypothesis was that a high incidence of symptoms would be found in the two groups with a known OASIS, a hypothesis that held true. As we expected, women in group 3 reported almost no symptoms. Interestingly, women in group 4 reported symptoms to some extent which might be an indication of missed injuries. Since the study is not dealing with causalities there is a risk that it might reveal women with comorbidities.

In Sweden the incidence of obstetric anal sphincter injuries, OASIS, in each delivery department is reported annually to the Swedish National Board of Health and Welfare and a low incidence is considered to be an indicator of good quality of obstetric care. Until recently, this report has merely been a concern for each department, but during the latest years the figures have been published in the newspapers, and since 2009 there is open competition between the six delivery departments, where a low OASIS figure could be presented as a benefit when offering obstetric care. Worldwide, there are reports of increasing incidence of OASIS. Studies have been presented revealing increasing incidence in the event of women going through thorough reexamination by an experienced clinician immediately after delivery, $[13,14]$. It is thus possible that an increasing incidence may merely reveal a high level of knowledge about the condition.

It is most important to prevent any birth trauma if possible but the worse trauma is that which has not been detected and treated. An evaluation of women's experience of short-and/or long-term pelvic floor symptoms after delivery would be more valuable as an indicator of quality of obstetric care than the reported incidence alone.

The strength of the present study is that the population consisted of a sample of all primiparas who gave birth in Stockholm during the study period and the fact that all women who sustained a complete OASIS were invited to participate in the survey. Moreover, the division of OASIS into two subgroups might allow us to reason around contingent differences between symptoms following these two injuries. This distinction is rare in previous literature. We also involved two well-defined control groups. Another strength is that the mean age of the groups is approximately the same. The study does not however deal in any way with causalities such as maternal age, fetal size, or comorbidities but only with the possibility of identifying pelvic floor symptoms probably caused by delivery.

Two thirds of the women were university graduates, a figure that reflects the educational level in large cities in
Sweden and indicates that we reached a representative sample of women giving birth in Stockholm. The period 12-18 months after delivery for the short-time follow-up was selected arbitrarily due to the fact that most women had been menstruating for some periods at 1 year postpartum but had still not delivered a second time. The result of the questionnaire will if used, provide the delivery department with fairly swift feedback. On the other hand, a weakness of the study was the low response rate which raised the suspicion that non-responders had few symptoms of pelvic floor dysfunction.

The groups did not differ regarding urinary incontinence before delivery. It is well-established that the prevalence of UI varies greatly depending on study group, definitions and methods used [22]. The prevalence of urinary incontinence during pregnancy is reported to be as high as $44 \%$ and between $7 \%$ and $34 \%$ [22] after delivery. Fornell et al. [19] suggest "incontinence once a week or more often" as a measure of incontinence in populations where objective signs are not available on record". Using this cut-off there is significantly less SUI in the electively operated group (group 3) which is in accordance with previous studies [23, 24]. Sheer et al. [22] who examined women 10 weeks postpartum and used a well-defined control group with no missed injuries of the anal sphincter, noted urinary leakage more often among women with known OASIS. The association between OASIS and SUI remains to be determined but one hypothesis is that extensive soft tissue trauma may also afflict the structures of the urethral supportive mechanisms $[25,26]$.

In previous studies the sense of vaginal bulge has been shown to correlate with clinically significant prolapse [17]. A correlation between excessive stretching and tearing and POP (pelvic organ prolapse) later in life has been found [25-27]. In our study the sense of bulging was most often reported by the women with a complete OASIS. We found it noteworthy that as many as $4.5 \%$ of patients with, what we believe to be smaller lacerations, nevertheless report prolapse symptoms as soon as $12-18$ months after delivery. The current classification of vaginal tears may be insufficient, as it focuses on the anal sphincter and perineum only, leaving lacerations in the other compartments of the pelvic floor without thorough description and classification.

Involuntary gas leakage was frequent in both groups 1 and 2 but also afflicted about one third of the women in groups 3 and 4 . There are problems with the concept of gas incontinence since passing gas is a physiological function and therefore gas incontinence cannot be defined in the same obvious way as stools incontinence. Our figures are, nevertheless, concurrent with previous studies [16, 28, 29].

It has been shown that anal incontinence after delivery is associated with increasing size of the internal anal sphincter defect $[30,31]$. In our study, leakage of liquid stools 
occurred rather frequently in both groups 1 and $2(17.7 \%$ and $17.0 \%$, respectively) but also occurred among women delivered vaginally with no known OASIS. The explanation to this might be the difficulty of detecting these injuries but also that the mechanisms behind anal incontinence after childbirth are not yet fully understood.

The fact that no one in group 1 reported solid stool incontinence raises the question as to whether the questionnaire did not accurately measure what it was supposed to measure. Perhaps large tears are more easily detected and thereby have a better chance of optimal attention, suturing and postpartum advice. Among women with a partial rupture and moreover, among women with a vaginal delivery with no reported OASIS a fairly large number reported leakage. This might indicate that the diagnosis in some cases had been missed.

Since the incidence of OASIS is used as a measurement of quality of care there might be a disincentive to document these injuries correctly. It is apparent from this study, that symptoms of PFD also occur in women with perineal tears that are considered uncomplicated. We thus suggest that it is necessary not only to report the incidence of OASIS, but also to evaluate the pelvic floor symptoms among women after childbirth. Furthermore, high detection rates may indicate attention and knowledge about the condition and thereby a greater possibility to prevent symptoms of anal incontinence due to missed OASIS [15]. This questionnaire focusing on women's symptoms a year after delivery contributes important information towards achieving this goal, seems to identify expected symptoms with reasonable accuracy and may therefore be utilized as a measurement of quality of care and feedback to obstetrical practices.

Acknowledgements We are grateful to Elisabeth Persson, MD, Ph.D. for her generous support when we initiated the study and to Katarina Selling, Statisticon AB, Stockholm, for her excellent advice on the statistics.

\section{Conflicts of interest None.}

Contribution All four authors have made substantial contributions to conception and design, acquisition of data, and to analysis and interpretation of data; all authors have drafted the article and reviewed it critically for important intellectual content; and left final approval of the version to be published.

Details of ethical approval The study was approved by The Ethics Committee at Karolinska Institutet (2007/1228-31/4 31st Oct 20

Funding This study was supported by the Divisions of Obstetrics and Gynecology of Södersjukhuset, Karolinska University Hospital, Danderyds Hosptial, Södertälje Hospital, and BB Stockholm
Open Access This article is distributed under the terms of the Creative Commons Attribution Noncommercial License which permits any noncommercial use, distribution, and reproduction in any medium, provided the original author(s) and source are credited.

\section{References}

1. Rothbarth J, Bemelman WA, Meijerink WJ, Stiggelbout AM, Zwinderman AH, Buyze-Westerweel ME, Delemarre JB (2001) What is the impact of fecal incontinence on quality of life? Dis Colon Rectum 44:67-71

2. Roos AM, Sultan AH, Thakar R (2009) St. Mark's incontinence score for assessment of anal incontinence following obstetric anal sphincter injuries (OASIS). Int Urogynecol J Pelvic Floor Dysfunct 20:407-410

3. Due U, Ottesen M (2009) The Danish anal sphincter rupture questionnaire: validity and reliability. Acta Obstet Gynecol Scand 88:36-42

4. Pauls RN, Occhino J, Dryfhout V, Karram MM (2008) Effects of Pregnancy on Body Image and Pelvic floor dysfunction; a prospective study. Int Urogynecol J Pelvic Floor Dysfunct 19 (11):1495-1501

5. Snooks SJ, Swash M, Mathers SE, Henry MM (1990) Effect of vaginal delivery on the pelvic floor: a 5-year follow-up. Br J Surg 77:1358-1360

6. Sultan AH, Kamm MA, Hudson CN, Thomas JM, Bartram CI (1993) Anal-sphincter disruption during vaginal delivery. N Engl J Med 329:1905-1911

7. Sultan AH, Kamm MA, Hudson CN (1994) Pudendal nerve damage during labour: prospective study before and after childbirth. Br J Obstet Gynaecol 101:22-28

8. Pirhonen JP, Grenman SE, Haadem K, Gudmundsson S, Lindqvist P, Siihola S, Erkkola RU, Marsal K (1998) Frequency of anal sphincter rupture at delivery in Sweden and Finland - result of difference in manual help to the baby's head. Acta Obstet Gynecol Scand 77:974-977

9. Zetterstrom J, Lopez A, Anzen B, Norman M, Holmstrom B, Mellgren A (1999) Anal sphincter tears at vaginal delivery: risk factors and clinical outcome of primary repair. Obstet Gynecol 94:21-28

10. Faltin DL, Otero M, Petignat P, Sangalli MR, Floris LA, Boulvain M, Irion O (2006) Women's health 18 years after rupture of the anal sphincter during childbirth: I. Fecal incontinence. Am J Obstet Gynecol 194:1255-1259

11. Poen AC, Felt-Bersma RJ, Dekker GA, Deville W, Cuesta MA, Meuwissen SG (1997) Third degree obstetric perineal tears: risk factors and the preventive role of mediolateral episiotomy. Br J Obstet Gynaecol 104:563-566

12. Sultan AH, Kamm MA, Hudson CN, Bartram CI (1994) Third degree obstetric anal sphincter tears: risk factors and outcome of primary repair. BMJ 308:887-891

13. Groom KM, Paterson-Brown S (2002) Can we improve on the diagnosis of third degree tears? Eur J Obstet Gynecol Reprod Biol 101:19-21

14. Andrews V, Sultan AH, Thakar R, Jones PW (2006) Occult anal sphincter injuries - myth or reality? BJOG 113:195-200

15. Faltin DL, Boulvain M, Floris LA, Irion O (2005) Diagnosis of anal sphincter tears to prevent fecal incontinence: a randomized controlled trial. Obstet Gynecol 106:6-13

16. Fornell EK, Berg G, Hallbook O, Matthiesen LS, Sjodahl R (1996) Clinical consequences of anal sphincter rupture during vaginal delivery. J Am Coll Surg 183:553-558 
17. Tegerstedt G, Miedel A, Maehle-Schmidt M, Nyren O, Hammarstrom M (2005) A short-form questionnaire identified genital organ prolapse. J Clin Epidemiol 58:41-46

18. Eliasson K, Nordlander I, Mattsson E, Larson B, Hammarstrom M (2004) Prevalence of urinary leakage in nulliparous women with respect to physical activity and micturition habits. Int Urogynecol J Pelvic Floor Dysfunct 15:149-153

19. Uustal Fornell E (2003) Pelvic floor dysfunction: a clinical and epidemiological study. Univ, Linköping

20. Jorge JM, Wexner SD (1993) Etiology and management of fecal incontinence. Dis Colon Rectum 36:77-97

21. Fernando RJ, Sultan AH, Kettle C, Radley S, Jones P, O'Brien PM (2006) Repair techniques for obstetric anal sphincter injuries: a randomized controlled trial. Obstet Gynecol 107:1261-1268

22. Scheer I, Andrews V, Thakar R, Sultan AH (2008) Urinary incontinence after obstetric anal sphincter injuries (OASIS) - is there a relationship? Int Urogynecol J Pelvic Floor Dysfunct 19:179-183

23. Glazener CM, Herbison GP, MacArthur C, Lancashire R, McGee MA, Grant AM, Wilson PD (2006) New postnatal urinary incontinence: obstetric and other risk factors in primiparae. BJOG 113:208-217

24. Farrell SA, Allen VM, Baskett TF (2001) Parturition and urinary incontinence in primiparas. Obstet Gynecol 97:350-356
25. Fritsch H, Pinggera GM, Lienemann A, Mitterberger M, Bartsch G, Strasser H (2006) What are the supportive structures of the female urethra? Neurourol Urodyn 25:128-134

26. Dietz HP, Lanzarone V (2005) Levator trauma after vaginal delivery. Obstet Gynecol 106:707-712

27. Tegerstedt G, Miedel A, Maehle-Schmidt M, Nyren O, Hammarstrom M (2006) Obstetric risk factors for symptomatic prolapse: a population-based approach. Am J Obstet Gynecol 194:75-81

28. Wagenius J, Laurin J (2003) Clinical symptoms after anal sphincter rupture: a retrospective study. Acta Obstet Gynecol Scand 82:246-250

29. Poen AC, Felt-Bersma RJ, Strijers RL, Dekker GA, Cuesta MA, Meuwissen SG (1998) Third-degree obstetric perineal tear: longterm clinical and functional results after primary repair. Br J Surg 85:1433-1438

30. Vaccaro C, Clemons JL (2008) Anal sphincter defects and anal incontinence symptoms after repair of obstetric anal sphincter lacerations in primiparous women. Int Urogynecol J Pelvic Floor Dysfunct 19:1503-1508

31. Mahony R, Behan M, Daly L, Kirwan C, O'Herlihy C, O'Connell PR (2007) Internal anal sphincter defect influences continence outcome following obstetric anal sphincter injury. Am J Obstet Gynecol 196(217):e211-e215 